\title{
NUMERICAL MODELING OF VERTICAL WELLS IN UNSTEADY GROUNDWATER FLOW CONDITIONS
}

\author{
TOMASZ STRZELECKI, EUGENIUSZ SAWICKI \\ Institute of Geotechnics and Hydrotechnics, Wrocław University of Technology, \\ Wybrzeże Wyspiańskiego 27, 50-370 Wrocław, Poland. \\ E-mail: tomasz.strzelecki@pwr.wroc.pl, eugeniusz.sawicki@pwr.wroc.pl \\ MiCHAE STRZELECKI \\ KGHM CUPRUM Ltd. Research and Development Centre, \\ ul. Gen. Wł. Sikorskiego 2-8, 53-659 Wrocław, Poland. \\ E-mail: mstrzelecki@cuprum.wroc.pl
}

\begin{abstract}
This article presents the results of numerical calculations of drainage of a large engineering construction - "Afrykarium" in Wrocław ZOO, Poland, based on a 2D numerical model for seepage flow. In the numerical simulations the real (natural) hydrogeological conditions, water-courses, surface reservoirs and time dependent seepage flow (during drainage) are taken into account. The aim of numerical calculations was to determine quantities (draining time, number of wells, spacing and arrangement of wells, flows for every well, and hydraulic head map) necessary to design an effective drainage system of construction site. The mathematical model adopted to illustrate and predict groundwater depression during pumping was the Boussinesq equation for unsteady $2 \mathrm{D}$ flow.
\end{abstract}

\section{INTRODUCTION}

The aim of the calculations presented in this paper was to determine the parameters (such as draining time, number of wells, spacing and arrangement of wells, flows for every well, and hydraulic head map) necessary to design an effective drainage system of excavation for "Afrykarium" complex (for fauna and flora from Africa), in Wrocław ZOO, Poland. Digital terrain model (DTM) containing the excavation area (light grey on the right-hand side) to be drained, together with surrounding terrain is presented in Fig. 1. The area of the excavation is about 15300 squared meters and mean demanded depression is about 8.5 meters.

Together with an a priori adopted conception the draining excavation area was divided into eight sections (stages, Fig. 2). Due to the time pressure a decision that making a diaphragm wall, draining and digging should start almost simultaneously was made. Following the progress of building works, each section will be partially enclosed by a diaphragm wall and closed by a barrier of vertical wells, both diaphragm wall and vertical wells reaching the impervious layer of soil. The drainage of the whole excavation will occur gradually in eight stages (sections), section by section. After drainage of a selected section (for example, Section I = Stage I) the excavation and next slab should be done. (During construction works in Section I, Section II must be drained, and so on until de- 
manded depression is obtained). Because of the need to estimate the rate of water surface decrease and danger that the drained area will be supplied by Oder's waters (Fig. 1) a 2D numerical model for seepage flow was adopted and hence the DTM together with full hydro-geological conditions was also necessary.

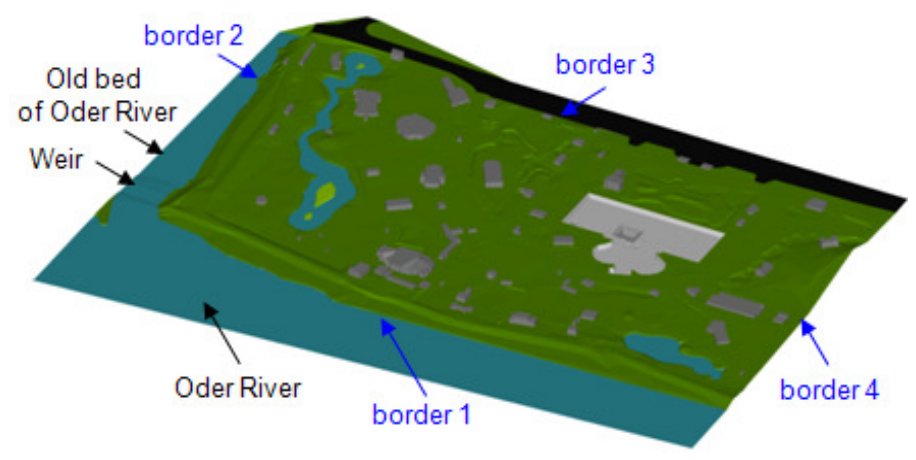

Fig. 1. Digital terrain model (DTM) containing the excavation area (light grey on the right-hand side) to be drained, together with surrounding terrain

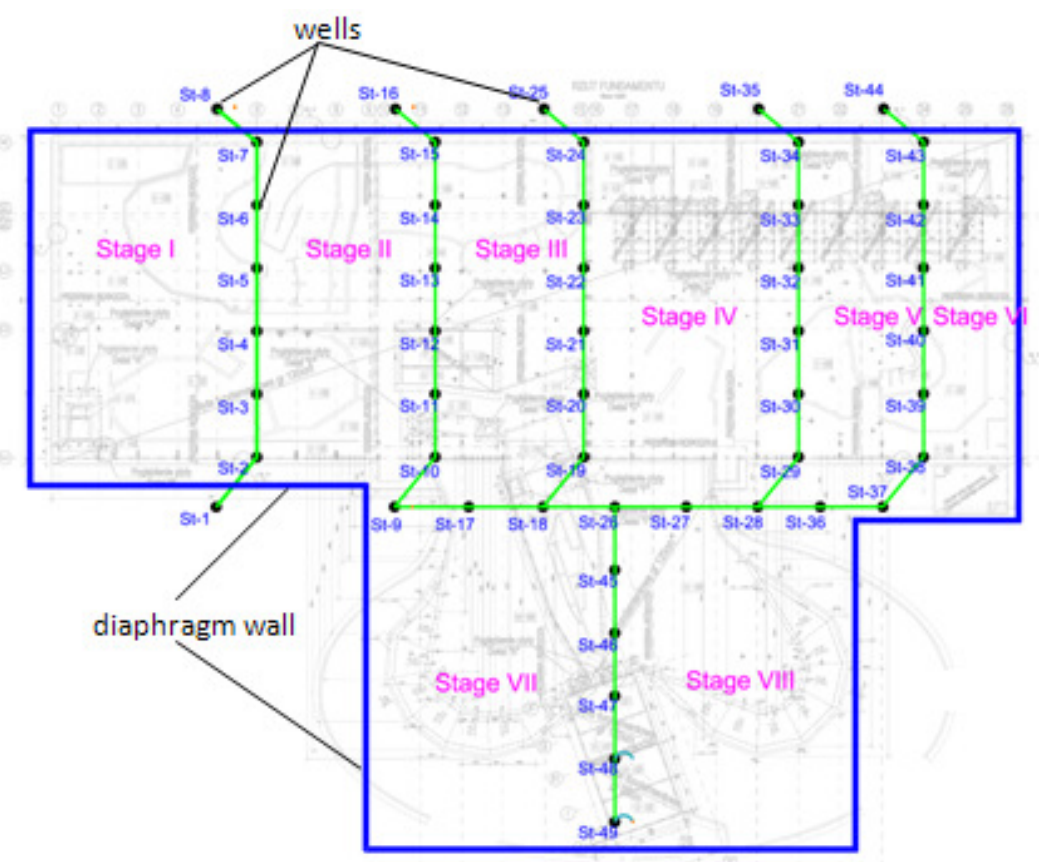

Fig. 2. The drainage process divided into eight stages, with each stage corresponding to one section of the baseplate 
As was mentioned earlier, the calculation results should provide appropriate information for each stage to determine the following parameters necessary to design an effective drainage system: draining time for current section, number of wells, spacing and arrangement of wells, flows for every well, and hydraulic head map.

In order to determine the above mentioned parameters a DTM containing the excavation and adjacent area was made, and the mathematical models were chosen.

Section 2 contains a description of hydro-geological conditions of the region. In Section 3, the adopted mathematical models and boundary conditions are presented. Section 4 contains a description of calculation process and results. Summary and conclusions are in Section 5.

\section{HYDRO-GEOLOGICAL CONDITIONS OF THE REGION}

It is known from the geological documentation that aquiferous layers of the building-site are formed from: medium sand, sand with gravel, gravel and gravel with cobble. There are also loams and clays in the form of large inclusions. In the whole terrain the floor of the aquifer $(\mathrm{Hs})$ is quite flat and goes down to ordinate about $106.5 \mathrm{~m}$ a.s.l. Below this value is a layer of loam which is regarded as impermeable in our calculations.

The terrain surface is permeable and rainwater can percolate through vadose zone to aquifer, hence the infiltration intensity $\varepsilon$ was introduced and established as equal to $3 \mathrm{e}-9 \mathrm{~m} / \mathrm{s}$.

On the basis of only few boreholes it was found that groundwater table is free and light tight and stabilizes on the ordinate 115.2 to $115.4 \mathrm{~m}$ a.s.l. There are also possible seasonal fluctuations of water table of about $0.5 \mathrm{~m}$. Because aquifers are hydraulically contacted and because they are composed of many different soils the mean permeability coefficient $(k)$ was adopted as equal to $6 \mathrm{e}-4 \mathrm{~m} / \mathrm{s}$. In other words, we assume that all existing geological layers can be substituted by one layer when permeability is isotropic and is described by the scalar coefficient $k$.

\section{ADOPTED MATHEMATICAL MODELS AND BOUNDARY CONDITIONS}

\subsection{ADOPTED MATHEMATICAL MODELS}

To design an appropriate drainage system, in the each calculation step, first we must determine and control basic information such as "shape" of the groundwater table (hydraulic head map). For this purpose, depending on the conditions, two mathematical models were adopted. 
The first one is the nonlinear Boussinesq equation [1], [2], [4], [5] for steady groundwater flow

$$
k=\frac{\partial}{\partial x}\left((H-H s) \frac{\partial(H-H s)}{\partial x}\right)+k \frac{\partial}{\partial y}\left((H-H s) \frac{\partial(H-H s)}{\partial y}\right)+\varepsilon=0
$$

where:

$H$ - hydraulic head relative to the adopted reference level (sea level),

$H s$ - aquifer bottom elevation above reference level (sea level),

$k$ - value of the averaged hydraulic conductivity,

$\mathcal{E}-$ infiltration intensity on the free surface,

$x, y$ - horizontal coordinates.

And the second one is also the nonlinear Boussinesq equation but for unsteady groundwater flow

$$
k\left[\frac{\partial}{\partial x}\left((H-H s) \frac{\partial(H-H s)}{\partial x}\right)+\frac{\partial}{\partial y}\left((H-H s) \frac{\partial(H-H s)}{\partial y}\right)\right]+\varepsilon=\mu_{e} \frac{\partial(H-H s)}{\partial t}
$$

where:

$\mu_{e}$ - aquifer effective porosity,

$t$ - time.

To show the velocity field the classic Darcy's law was applied, where the velocity vector $v$ is described as

$$
v=-k \cdot \operatorname{grad} H
$$

\subsection{BOUNDARY CONDITIONS}

Models (1), (2) need appropriate boundary conditions [4], [5]. Equation (1) allows us to determine the "shape" of the groundwater table in the steady state conditions. Remembering the assumption about isotropic permeability (Section 2) and because in the model (1) there are only two horizontal coordinates $(x, y)$ it is sufficient to impose the boundary conditions only on the borders: 1, 2, 3, 4 (Fig. 1). Nevertheless the solution generated by the model gives the distribution of the hydraulic head $H$ in the vertical direction $(z)$ and hence the groundwater table image is 3D (Figs. 4, 9).

In this case, on the borders 1 and 2, Dirichlet's boundary conditions should be adopted. Because along the banks of the Oder river the hydraulic head $H$ is equal to the water surface elevation in the river this condition was applied, wherein the difference between water surface elevation in the "new" and in the "old" bed of Oder due to weir was taken into account. We can say that hydraulic head $H$ is approximately 
$115.6 \mathrm{~m}$ on border 1 and about $112.0 \mathrm{~m}$ on border 2 . On the boundaries 3 and 4 the values of $H$ are a priori unknown and there is no reason to suppose that these borders are impermeable. So a generalized (unknown) flux boundary condition derived from the divergence theorem was imposed there. In FlexPDE 5 (the software used to perform numerical calculations) unknown generalized flux boundary condition is represented by the statement: $\operatorname{load}(\mathrm{H})=0$ (FlexPDE manual).

In the domain of interest there are also two surface reservoirs. The level of the water surface in the one on the left (the bigger one) is $115.1 \mathrm{~m}$, and in the second one on the right it is 115.2. These values were imposed respectively on the borders of each reservoir (Dirichlet's boundary condition).

Values of $\varepsilon$ and $k$ present in the model are described in Section 2.

The model (2), for unsteady groundwater flow, served to predict groundwater table during pumping when drainage system was active (Stage I to Stage VIII). In this case the boundary conditions were unchanged in relation to model (1) but initial boundary condition was added.

The solution of (1) is the hydraulic head map (in time $t=0$ ) which shows the distribution of $H$ in the whole domain of calculations, and hence this result was entered to the model (2) as an initial condition (for calculations of Stage I). It is worth mentioning that solution of Stage I was used such as an initial condition of Stage II, and so on.

Because in Stage I (and in the next ones as well, for example, Fig. 1, Fig. 6) both the diaphragm wall and wells appear, it is necessary to impose appropriate boundary conditions for these elements. The diaphragm wall is impervious (the flux through them is equal to zero) and Neumann condition is adopted here. The ordinate of the expected depression should not be higher than $106.5 \mathrm{~m}$ a.s.l. This last value was applied as the Dirichlet condition for every well introduced to the calculations.

\section{DESCRIPTION OF CALCULATION PROCESS AND RESULTS OBTAINED}

As was already mentioned at the beginning the aim of the calculations was to determine the quantities essential to design a drainage system: draining time, number of wells, spacing and arrangement of wells, flow for every well. Prior to calculations all necessary parameters were collected except the hydraulic head map (distribution of $H$ in the whole domain of interest).

Due to the time pressure a decision that making a diaphragm wall, draining and digging should start almost simultaneously was made. In accordance with this conception the construction domain was divided into eight stages (sections, Fig. 2). And following the progress of building works, the new sections should be gradually in- 
volved (attached) in the draining process.

So, to implement the above conception, in the first step the Digital Terrain Model (DTM) for the "Afrykarium" complex (excavation area, Fig. 1) and for the surrounding terrain was made.

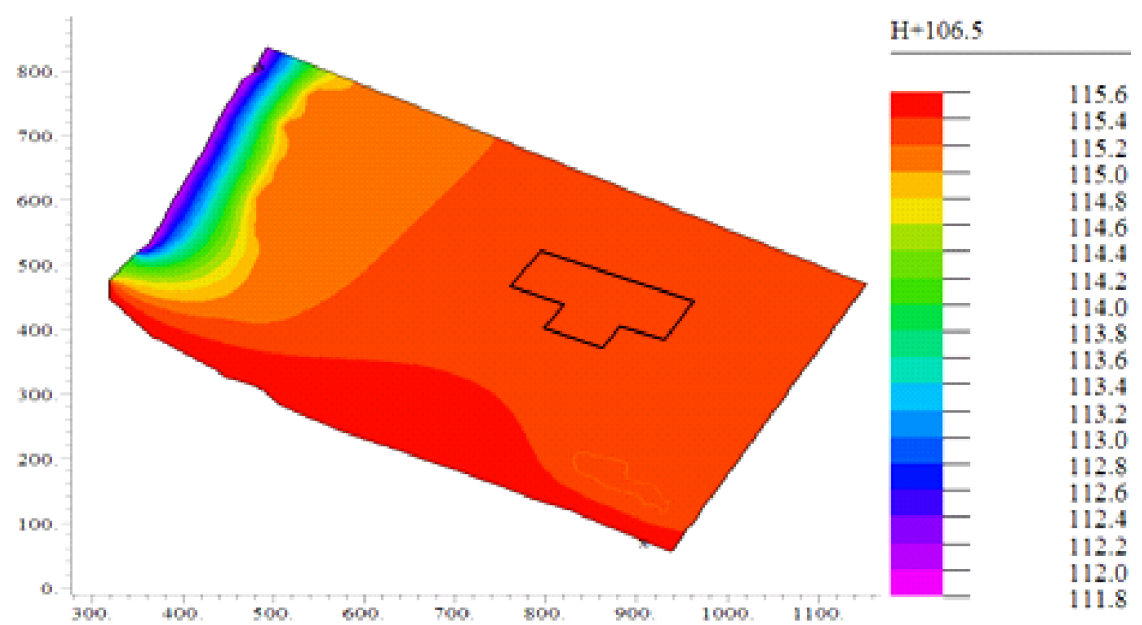

Fig. 3. The hydraulic head map for the whole domain of interest $(t=0)$. The black contour represents the construction site of "Afrykarium" complex

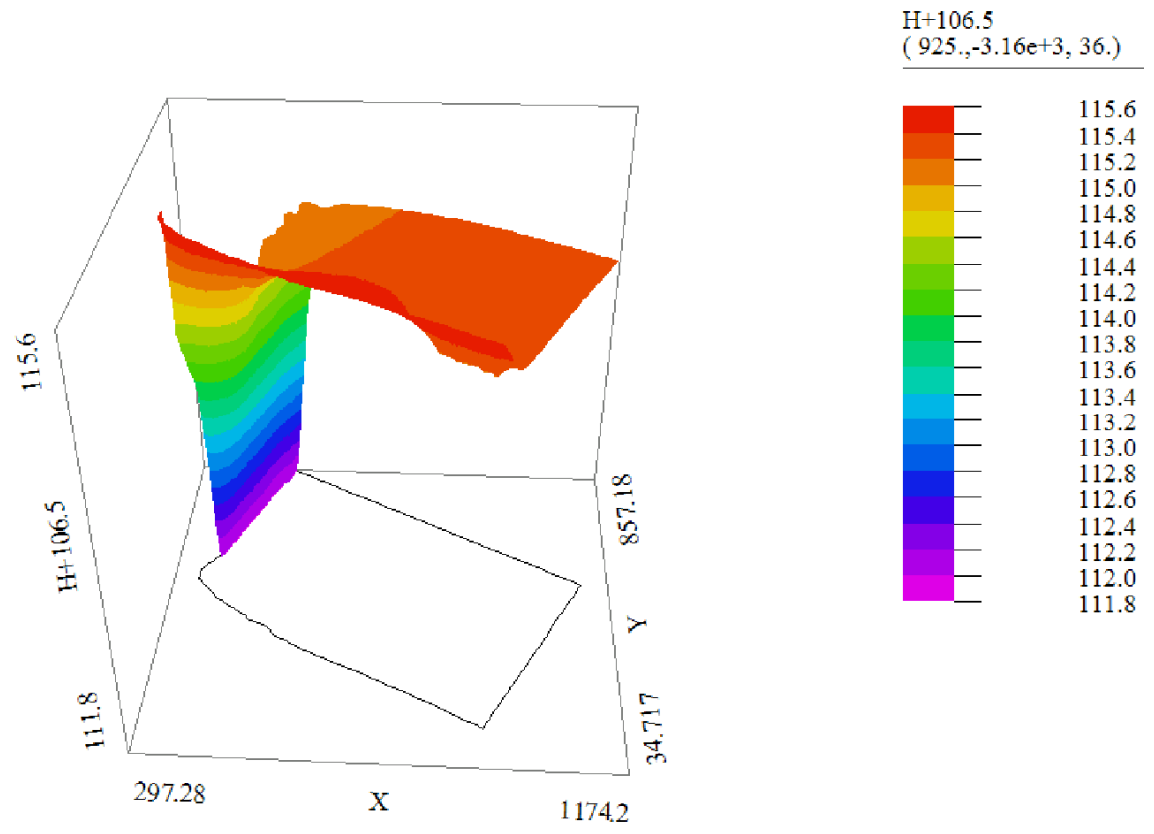


Fig. 4. 3D "shape" of the groundwater table for the whole domain of interest $(t=0)$

In the second step, it was necessary to determine the hydraulic head distribution in the whole domain without drainage. For this purpose the model (1) was used together with boundary conditions (Section 3). Every numerical simulation was made using FlexPDE 5 the finite element model builder for partial differential equations [3].

The results obtained are presented in Fig. 3 (hydraulic head map) and Fig. 4 where the $3 \mathrm{D}$ "shape" of the groundwater table is shown.

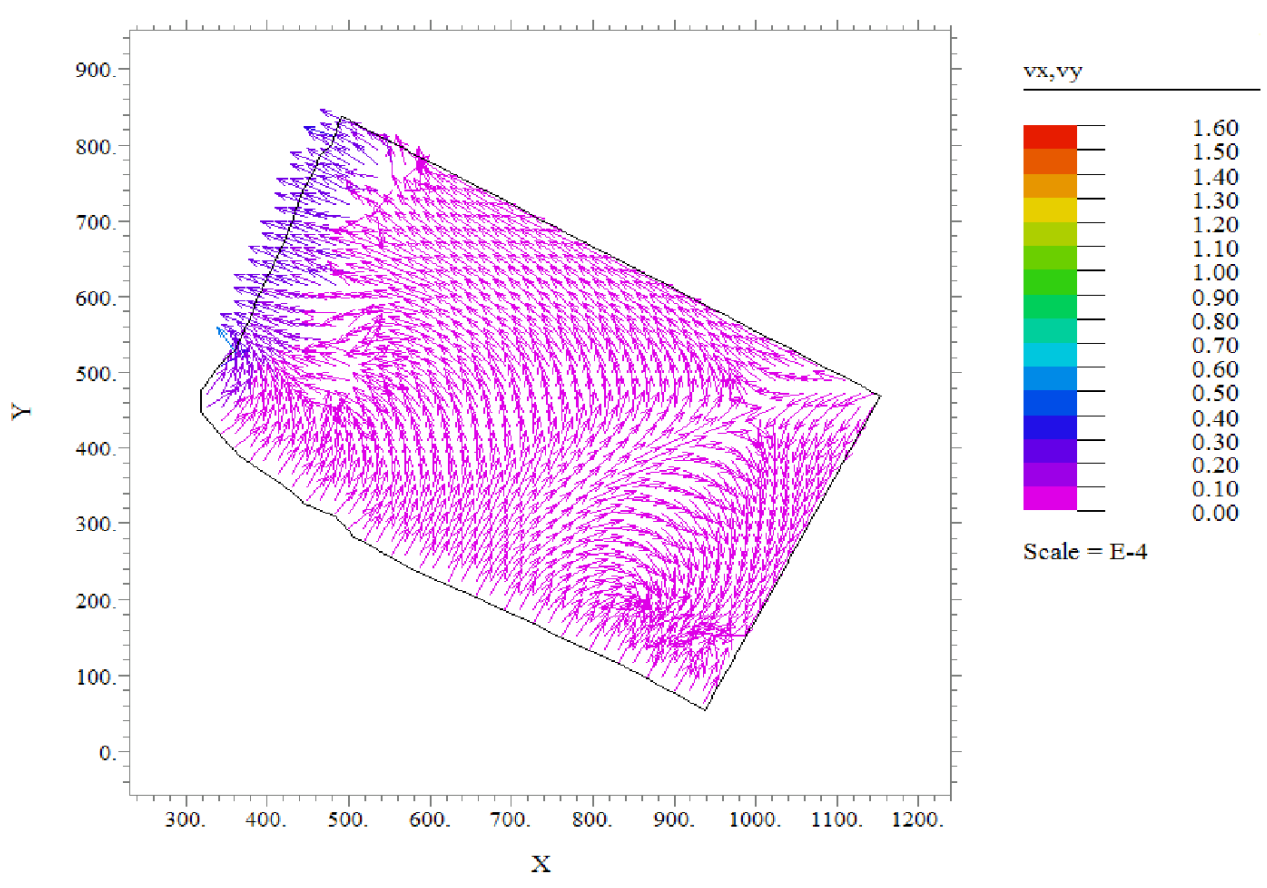

Fig. 5. The velocity field based on equations (1) and (3), ( $t=0)$

The black contour in Fig. 3 represents the construction site of "Afrykarium" complex. We can notice that values of hydraulic head inside this contour are between 115.2 and $115.4 \mathrm{~m}$ and correspond very well with hydro-geological observations described in Section 2. The correctness of the numerical simulations confirms also the velocity field free of unexpected perturbations (Fig. 5). In this situation any calibration of the model was not necessary.

Now, when the distribution of $H$ is known in the whole domain, it is possible to consider the first part of the drainage system. To make the calculations of Stage I (and successive Stages) the model (2) together with appropriate boundary conditions was used (Section 3). Changing the number of wells, their spacing and arrangement a satisfying depression for all simulated stages were found. The results obtained for Stage 
I are presented below.

In Fig. 6, the finite elements mesh for Stage I is shown.

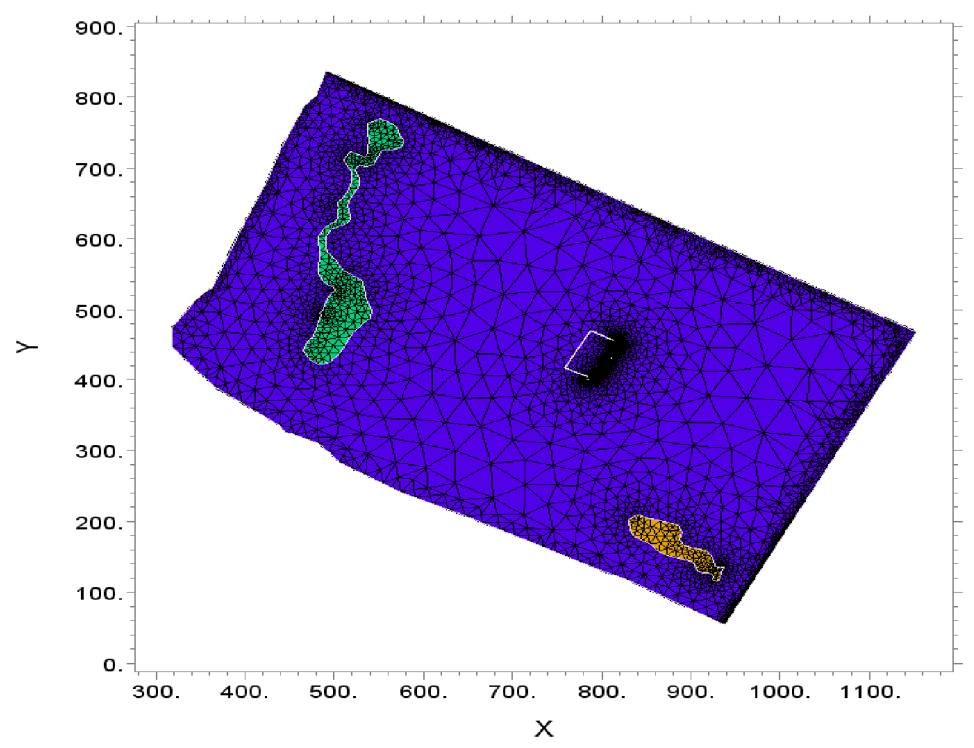

Fig. 6. Finite elements mesh for Stage I. 16836 nodes and 8300 elements

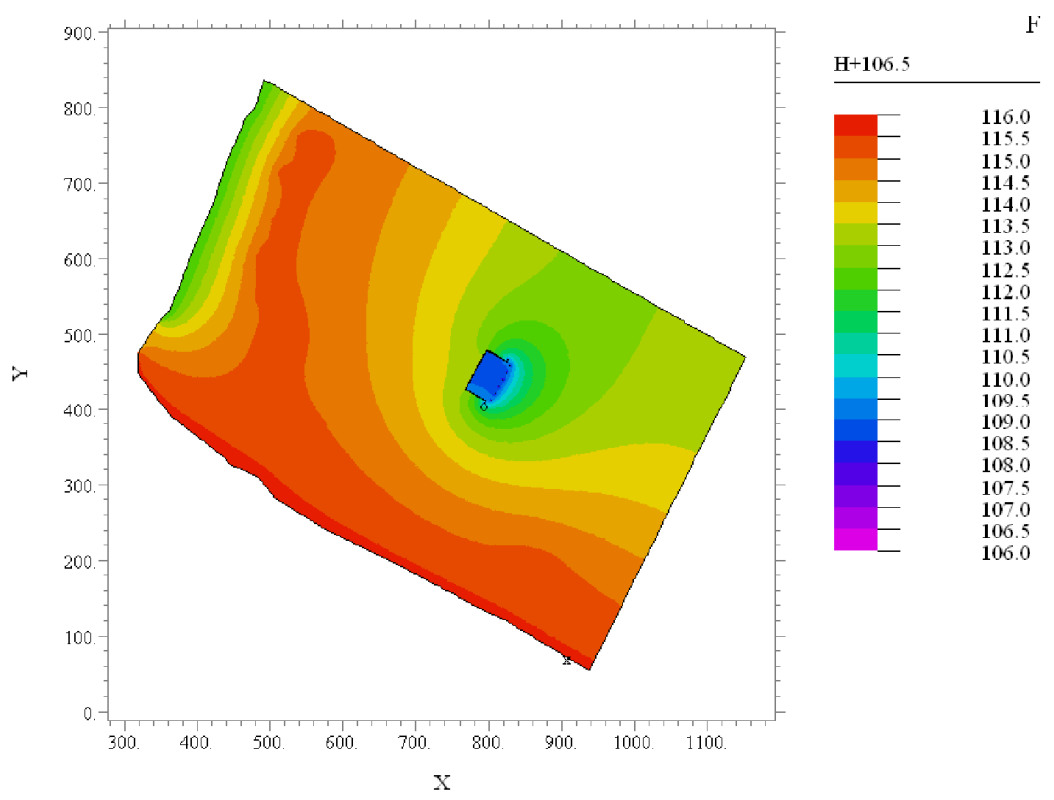

Fig. 7. The distribution of hydraulic head $H$ for the whole domain of interest, 


$$
t=6 \text { days (Stage } \mathrm{I} \text { ) }
$$

The distributions of hydraulic head: (i) for the whole domain and (ii) zoom of Section I of "Afrykarium" complex are presented in Fig. 7 and 8, respectively.

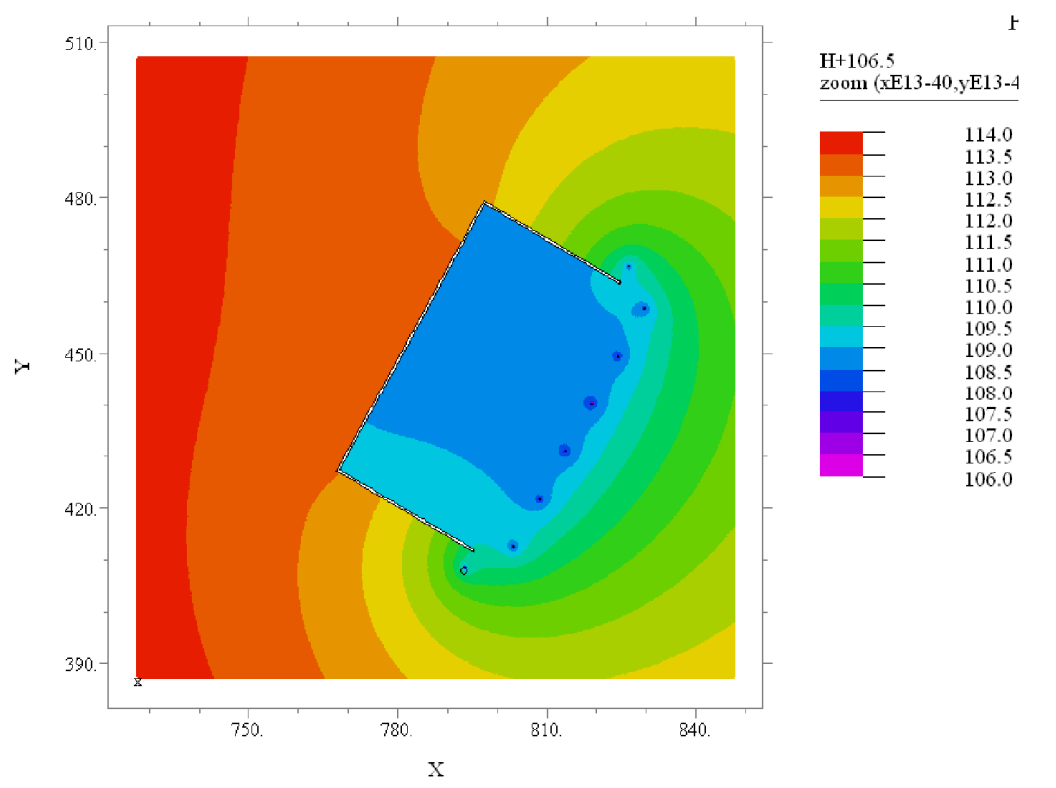

Fig. 8. The distribution of hydraulic head $H$ for the part of "Afrykarium" complex, zoom, $t=6$ days $($ Stage $\mathrm{I})$

The 3D visualization of groundwater table, velocity vectors and flux for every well (St-1 to St-8) are presented in Figs. 9 through 11.

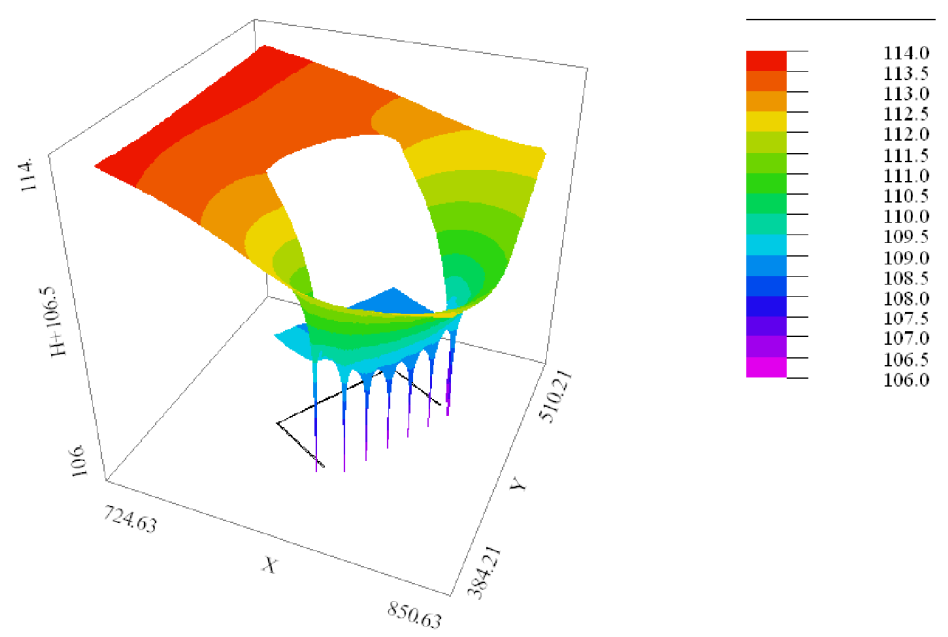


Fig. 9. 3D visualization of groundwater table, zoom, $t=6$ days (Stage I)

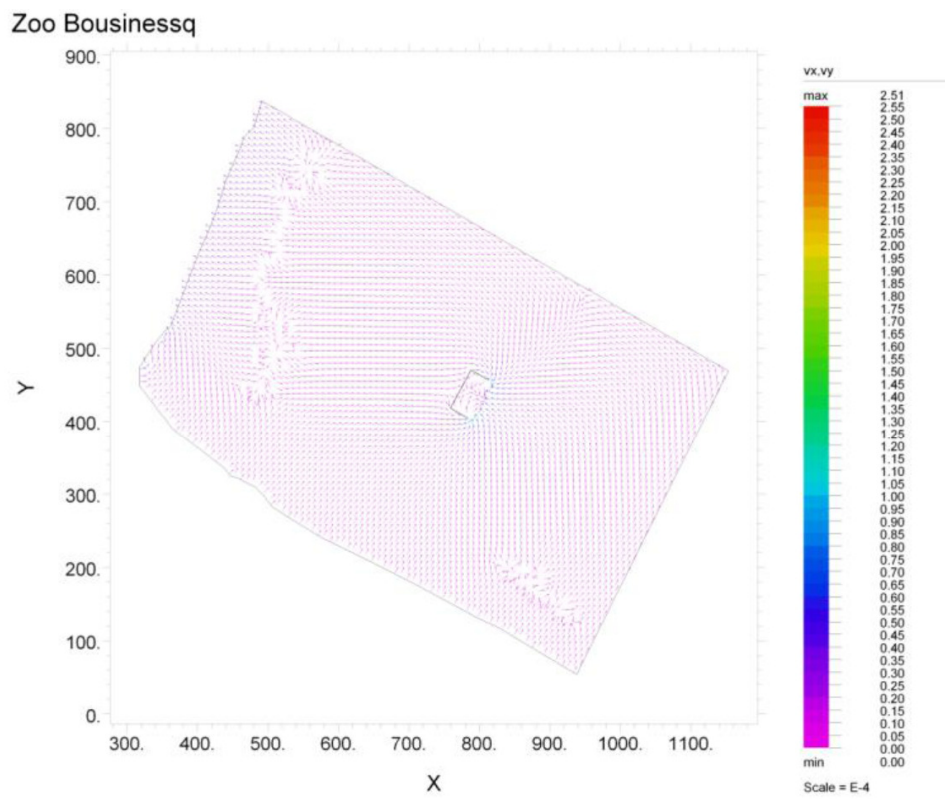

ZOO_ETAP I: Cycle $=127$ Time $=5.1840 \mathrm{e}+5 \mathrm{dt}=56234$. P2 Nodes $=15479$ Cells $=7631$ RMS Err $=0.0033$ $\mathrm{Q} 15=5.530258 \mathrm{e}-3 \quad \mathrm{Q} 16=6.070564 \mathrm{e}-3 \quad \mathrm{Q} 17=7.086907 \mathrm{e}-3 \quad \mathrm{Q} 18=8.571803 \mathrm{e}-3$

Fig. 10. Velocity vectors in the whole domain of interest, $t=6$ days (Stage I)

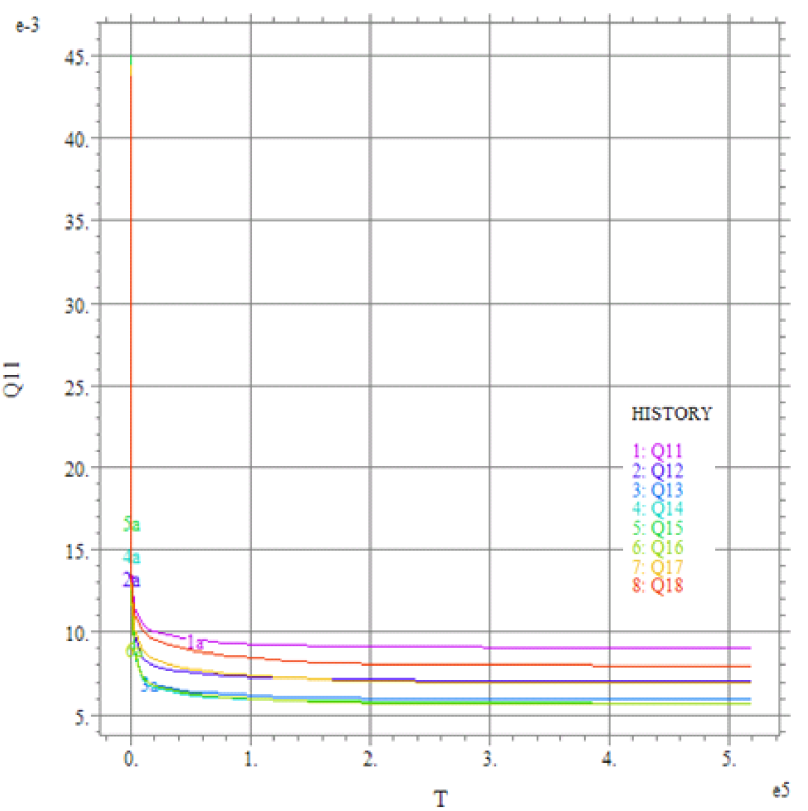


Fig. 11. Flux evolution in time during drainage process (Stage I)

In Fig. 12, the hydraulic head map for Stage VIII is shown. In this case, after 32 days of drainage (see also Table 1) the construction site should be completely closed by the diaphragm wall. The obtained ordinates of the depression are approximately equal to $106.5 \mathrm{~m}$ a.s.l. Thus the assumed level of depression is reached.

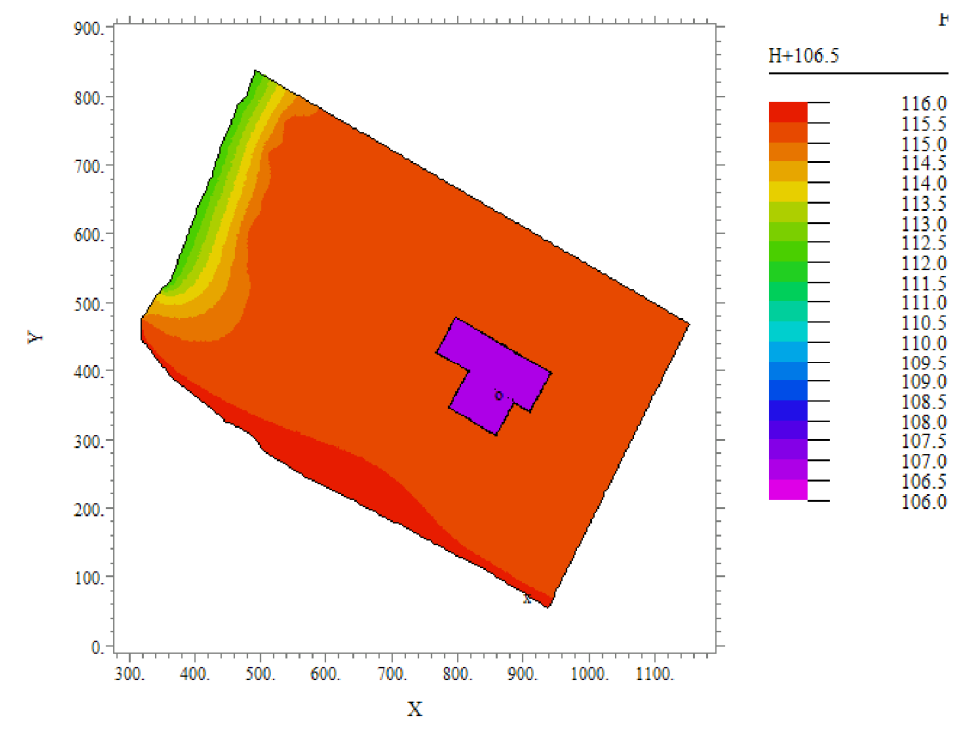

Fig. 12. The distribution of hydraulic head $H$ for the whole domain of interest (Stage VIII)

Finally, when numerical simulations are finished it is time to elaborate the results.

Table 1

List of results obtained for 8 Stages of drainage

\begin{tabular}{|c|c|c|c|c|}
\hline Stage & $\begin{array}{c}\text { Drainage time } \\
{[\text { days }]}\end{array}$ & $\begin{array}{c}\text { Number } \\
\text { of wells }\end{array}$ & $\begin{array}{c}\text { Total flux } \\
{\left[\mathrm{m}^{3} / \mathrm{s}\right]}\end{array}$ & $\begin{array}{c}\text { Expected depression } \\
{[\mathrm{m} \text { a.s.1.] }}\end{array}$ \\
\hline I & 6 & 8 & 0.055 & 109.0 \\
\hline II & 4 & 8 & 0.056 & 109.0 \\
\hline III & 4 & 10 & 0.064 & 108.8 \\
\hline IV & 4 & 13 & 0.077 & 108.6 \\
\hline V & 4 & 15 & 0.077 & 108.4 \\
\hline VI & 4 & 8 & 0.044 & 108.6 \\
\hline VII & 4 & 10 & 0.054 & 108.2 \\
\hline VIII & 2 & 4 & 0.002 & 106.6 \\
\hline
\end{tabular}

In Table 1, the principal quantities for each of the 8 stages are listed. These data together with the information about arrangement of wells, their number (from Fig. 2) 
constituted the base to carry out the design of drainage system for "Afrykarium" complex. It was established that to drain the domain of interest in 32 days 49 wells $(13 \mathrm{~cm}$ in diameter) are necessary, and the depression reached ordinate $106.5 \mathrm{~m}$.

On the basis of the distribution of hydraulic head the digital groundwater model (DGM) was built for every stage of drainage. Next, combining the DGM with digital slab model (DSM) and with digital terrain model (DTM) the visualization of groundwater surface with reference to DSM was possible. Figures 13 and 15 present such kind of visualization for Stage 1 and Stage 8, respectively. Additionally the crosssection A-A' for the same Stages (Figs. 14 and 16) gives us more detailed quantitative information about groundwater table with respect to DSM.

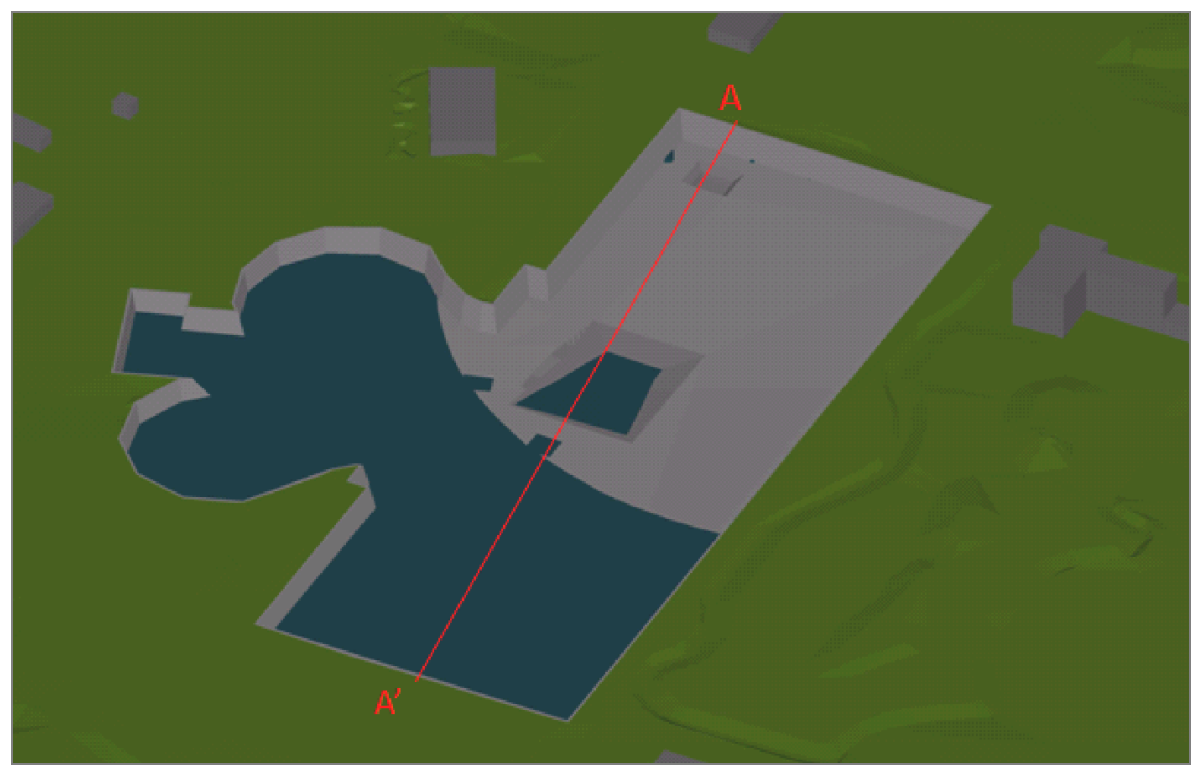

Fig. 13. Visualization of groundwater surface with reference to DSM (digital slab model), Stage I

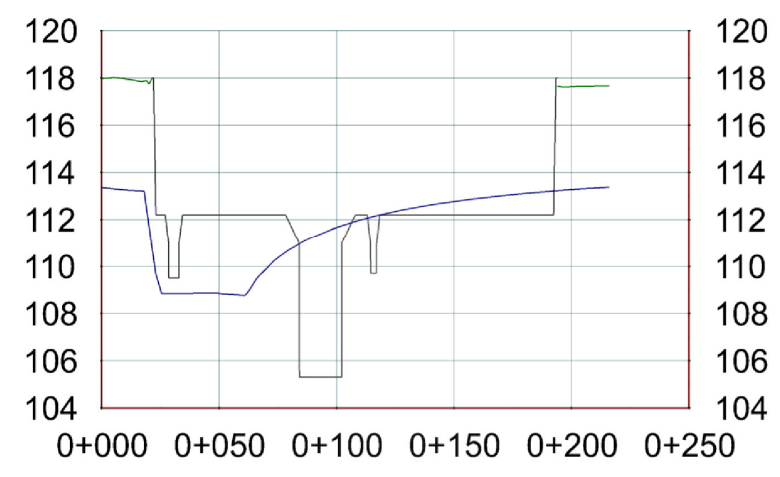


Fig. 14. Cross-section A-A', Stage I (see the text for more detailed description)

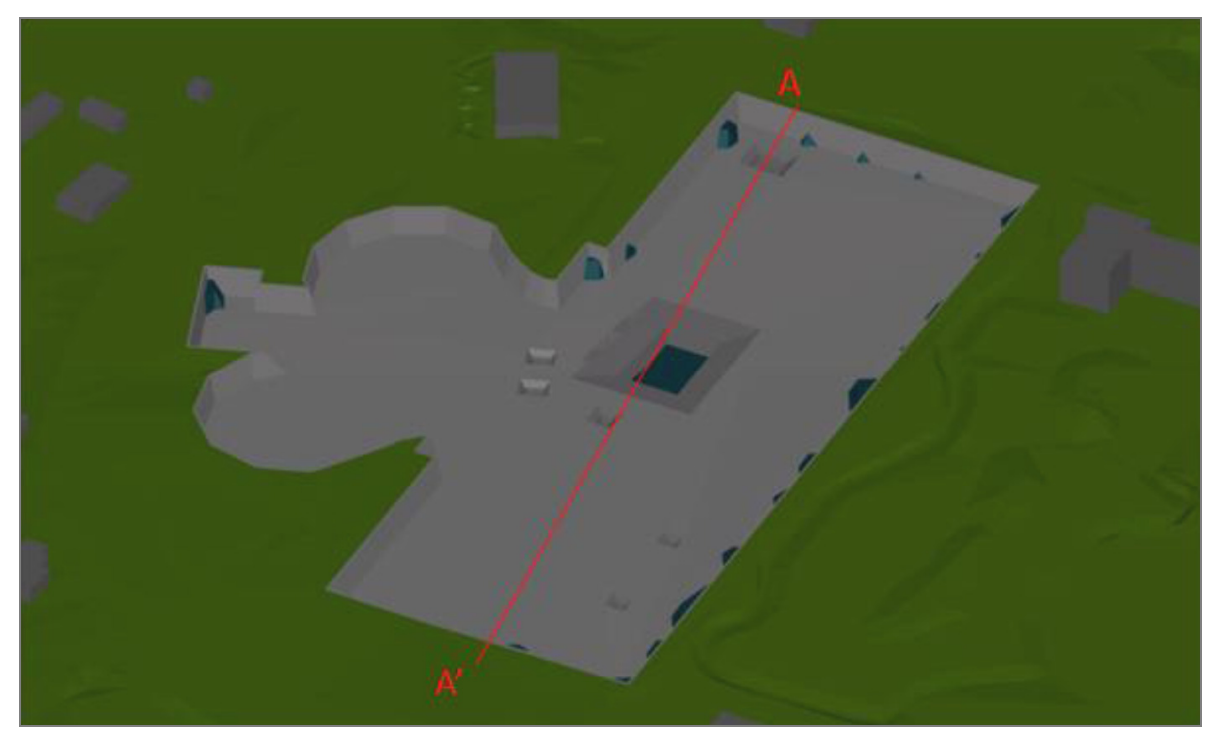

Fig. 15. Visualization of groundwater surface with reference to DSM (digital slab model), Stage VIII

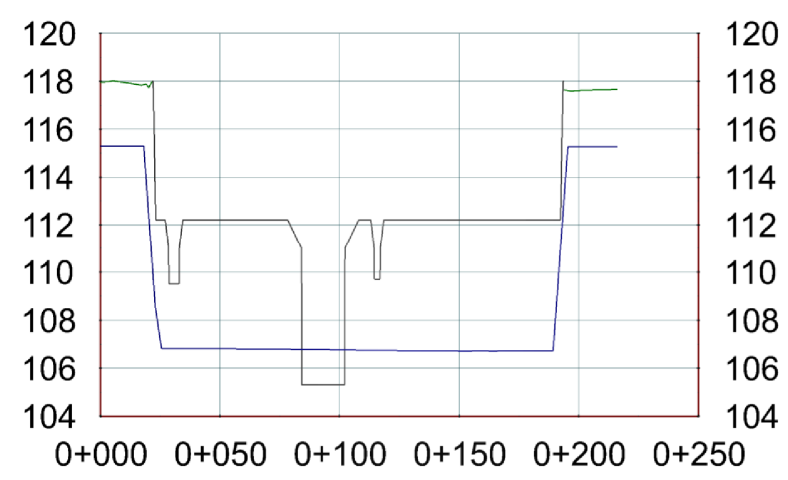

Fig. 16. Cross-section A-A', Stage VIII (see the text for more detailed description)

Analyzing the cross-section in Fig. 16 it became obvious that locally and for the deepest part of the slab leaks were possible and hence an additional drainage was necessary.

\section{SUMMARY AND CONCLUSIONS}

The calculations performed were divided into two parts. The first one allowed us 
to determine the distribution of hydraulic head in the whole domain of interest. We had noticed that obtained values in the region of excavation are in a very good accordance with the hydro-geological observations. Therefore we did not need to calibrate the first model (Boussinesq equation for steady flow), it worked very well, even in quite complicated hydraulic conditions.

Results from the first model provided the basis for the second part of numerical simulations divided into eight stages allowed us to determine the following quantities: draining time, number of wells, spacing and arrangement of wells, flows for every well, and depression, which formed the basis for the design of drainage system of "Afrykarium" complex.

The calculation showed that implementing 49 wells $(13 \mathrm{~cm}$ in diameter) will cause the depression to reach the ordinate $106.5 \mathrm{~m}$ in 32 days.

However, considering geological conditions and significant slab descent additional drainage will be necessary.

\section{REFERENCES}

[1] BEAR J., Hydraulics of groundwater, McGraw-Hill, Inc., New York, 1979.

[2] Hund-DER YeH, YA-CHI CHANG, Recent advances in modeling of well hydraulics, Advances in Water Resources, 2013, 51, 27-51.

[3] FlexPDE manual http://www.pdesolutions.com/

[4] Strzelecki T., KosteCKi S., ŻAK S., Modelowanie przeptywów przez ośrodki porowate, Dolnośląskie Wydawnictwo Edukacyjne, Wrocław, 2008.

[5] SzYmkiewicz R., Metody numeryczne w inżynierii wodnej, Wydawnictwo Politechniki Gdańskiej, Gdańsk, 2007. 